LA-UR $-91-7$
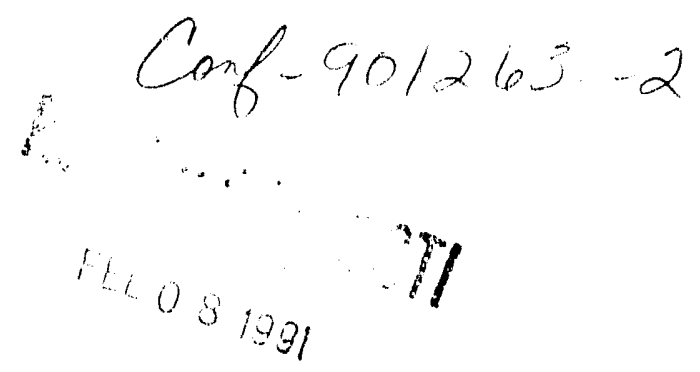

TITLE: DEVELOPMENT OF KrF LASERS FOR

INERTIAL CONFINEMENT FUSION

AUTHOR(S): J. A. Sullivan and D. B. Harris

$L A-U R--91-7$

DE9 1007349

$\begin{aligned} \text { AUThor(S): } & \text { J. A. Sullivan and D. } \\ \text { SUBMITtED To: } & \text { Lasers '90 Conference } \\ & \text { San Diego, CA } \\ & \text { December } 9-14,1990\end{aligned}$

\title{
DISCLAIMER
}

This report was prepared as an account of work sponsored by an agency of the United States Government. Neither the United States Government nor any agency thereof, nor any of their employees, makes any warranty, express or implied, or assumes any legal liability or responsibility for the accuracy, completeness, or usefulness of any information, apparatus, product, or proccss disclosed, or represents that its use would not infringe privately owned rights. Reference herein to any specific commercial product, process, or service by trade name, trademark, manufacturer, or otherwise does not necessarily constitute or imply its endorsement, recommendation, or favoring by the United States Government or any agency thereof. The views and opinions of authors expressed herein do not necessarily state or reflect those of the United States Government or any agency thereof.

By acceptance of this article, the publister recognizes that the U.S Government retains a nomexclusive. royalty-free Iicense to publish or reproduce the published form of inis contribution. Or 10 oflow others 10 do 0 . for U.S. Government purposes.

The Los ilamos National Laboratory requests that the publisher identify this article as work pertormed under the auspices of the U.S Oepartment of Energy WTSTER

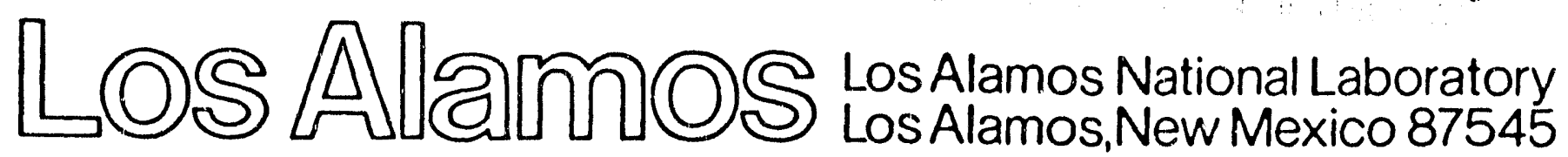




\section{Development of KrF Lasers for Inertial Confinement Fusion}

J. A. Sullivan and D. B. Harris

Lasers 90 Conference

San Diego, California

December 9 - 14, 1990 


\title{
Development of KrF Lasers for Inertial Confinement Fusion
}

\author{
J. A. Sullivan and D. B. Harris
}

\begin{abstract}
Recent reviews of the Inertial Confinement Fusion (ICF) program have resulted in recommendations that promise to focus the research effort on the examination of the feasibility of pellet ignition at $1 \mathrm{MJ}$ of energy on target. If successful, the next major step in the program has been defined to be the construction of an Ignition Facility. Los Alamos National Laboratory has developed a plan to reach single-pulse multimegajoule ICF facilities using the electronbeam-pumped KrF laser. The Los Alamos plan, its relation to the development of ICF for energy production, and the major features and design issues associated with ICF drivers will be covered in this presentation.
\end{abstract}

Submitted to the

Laser 90 Conference

December 9 - 14, 1990 
Introduction

Since the last review by the National Academy of Sciences in 1986 the ICF program has made very significant progress. In a series of underground tests at the Nevada Test Site the fundamental feasibility of ICF was demonstrated in a joint Los Alamos/Lawrence Livermore National Laboratory program called Centurian/Halite. This result as well as the achievement of significant target compressions in direct-drive experiments were in part responsible for an additional program review by the National Academy in 1990. A inajor recommendation by the most recent review was that the ICF program should concentrate on acquiring sufficient data from existing target facilities to affirm that ignition is possible at about the 1-MJ level. Other recommendations by the iNAS Committee have resulted in significant program plan rethinking.

In this paper we will point out the national ICF program directions and show how the KrF program fits within the national effort for both defense and energy applications of ICF.

The features of an ideal ICF driver will be reviewed, and we will briefly point out how the performance characteristics of KrF lasers compare to the ideal. Finally, we will summarize the technology developments that will result in significant cost reductions for KrF lasers.

Over the past two years the DOE defense ICF program has been working with laboratories funded to perform ICF driver research to define a "Laboratory Microfusion Facility" (LMF). The LMF was to operate with high gain $(\sim 100)$ with an input energy on target of about $10 \mathrm{MJ}$. The LMF is envisioned as the ICF program goal after demonstrating ignition.

\section{Observations on NAS Committee Findings}

At the risk of being taken out of context, we have taken some of the important statements directly from the NAS Committee final report and present them here as Figure 1. The most significant of these for the future of ICF is recognition that the near-term goal of the program should be to reach ignition and modest gain in the laboratory. The achievement of this goal will require successful target performance validation tests on NOVA and other ICF facilities. If successful, these experiments would support the construction of an ICF driver at the next energy plateau (1 MJ) that would be used to achieve ignition and modest gain. Because of the maturity of the glass laser technology over other candidate drivers, the Committee concluded that it would be the most likely to succeed on a short time scale. 
- The Committee was impressed by the high level of science and technology in the ICF program."

- "A second review three years after the Happer Report was undoubtedly stimulated by very positive results obtained during the interval and by growing interest within the ICF community in selecting and buiding a driver at the next energy plateau."

- "Further work in the Centurian/Halite program of underground experiments has shown qualitatively that the basic concept behind ICF is sound."

- "A significant near-term goal of the ICF program should be to achieve ignition and modest gain (2-10) in the laboratory by a dedicated effort using a largely renovated NOVA."

- "Ignition would open a new and important way to study thermonuclear phenomena in the laboratory."

- "The program is now at a point where, with adequate funding, the physics and driver technology could be in place in a few years for a firm decision whether to proceed with an ignition demonstration facility, and subsequently a larger facility, whether for defense or IFE."

- While success with a glass laser appears likely, it is not certain. Experiments in the next few years might not turn out as expected; the required driver performance might prove to be too costly (or even impossible) to achieve, or suitable targets may not be available. Moreover, gluss lasers are unsuited for IFE; the efficiency and pulse repetition rate of $\mathrm{KrF}$ lasers and heavy- and light-ion accelerators makes them much more attractive for this application."

Figure 1. 1990 NAS Review Findings

The Committee made the observation that glass lasers are unsuited to energy applications of ICF. This leaves only the KrF laser driver as a contender for energy applications along with the heavy- and light-ion accelerators.

\section{National ICF Program Directions}

If funding levels appropriate are made available over the next few years, the NOVA laser will be converted to what is termed "precision NOVA," the Omega laser at the University of Rochester will be upgraded to $30 \mathrm{~kJ}$, the NIKE KrF laser 
at NRL will be completed on an accelerated time schedule, and the development of energy applications of ICF will be funded. Precision NOVA is needed to validate target performance that would support ignition and modest target gain at $\sim 1-\mathrm{MW}$ driver energy using indirect drive. The Omega laser upgrade is designed for direct-drive experiments. The experiments on Omega, if successful, could result in the prediction that ignition and modest gain are possible at the few-hundred-kilojoule energy level. The NIKE KrF laser will also be configured to demonstrate the effect of beam smoothing on target performance. The smoothing technique to be incorporated is induced spatial incoherence. Los Alamos will work closely with NRL to help speed up the program and to help assure performance success. Los Alamos will also work closely with Livermore to field and interpret the target experiments on precision NOVA.

The NAS Committee recommended that the light-ion program at Sandia National Laboratories continue for two more years, with a review in the summer of 1992. The review will determine if the persistent problems of insufficient ion focus capability and a suitable ion source can be overcome.

\section{KrF Development Strategy}

Because of their natural characteristics of short wavelength, achievable broad bandwidth, pulse shape flexibility, and scaiability to high energies, KrF lasers are superior to glass for ICF defense applications. The question that arises is, why inen did the NAS defacto select glass laser technology for advancement to the next energy plateau in the ICF drive to reach ignition? The reason appears to be that KrF laser technology is less mature than glass and thus appears to have higher cost and performance risk for achieving an ignition capability. it is not certain that targets will perform as expected with any driver candidate. The KrF laser currently appears to have the highest probability of success because it best satisfies the target requirements. In view of this, we believe it is imperative that the KrF technology be advanced and evaluated simultaneously with glass for application in an ignition facility. It is worthy of note that the Fusion Policy Advisory Committee identified KrF as the only laser having characteristics suitable for energy production.

A viable strategy for the simultaneous evaluation of $\mathrm{KrF}$ and $3 \omega \mathrm{Nd}$ :glass is depicted in Figure 2. This approach advocates the review of precision NOVA experiments and the results achieved with the NRL NIKE laser. A decision as to which technology to pursue for an ignition facility could be made in $\sim 1995$.

For energy applications of ICF using KrF lasers, the near-term approach should be a demonstration that the efficiericy and beam quality required to permit the large stand-off distances for the final optics can be achieved. Such a demonstration appears feasible with modifications of the existing EMRLD laser that AVCO constructed for the Air Force at White Sands Missile Range or a similar device. Activation of this 


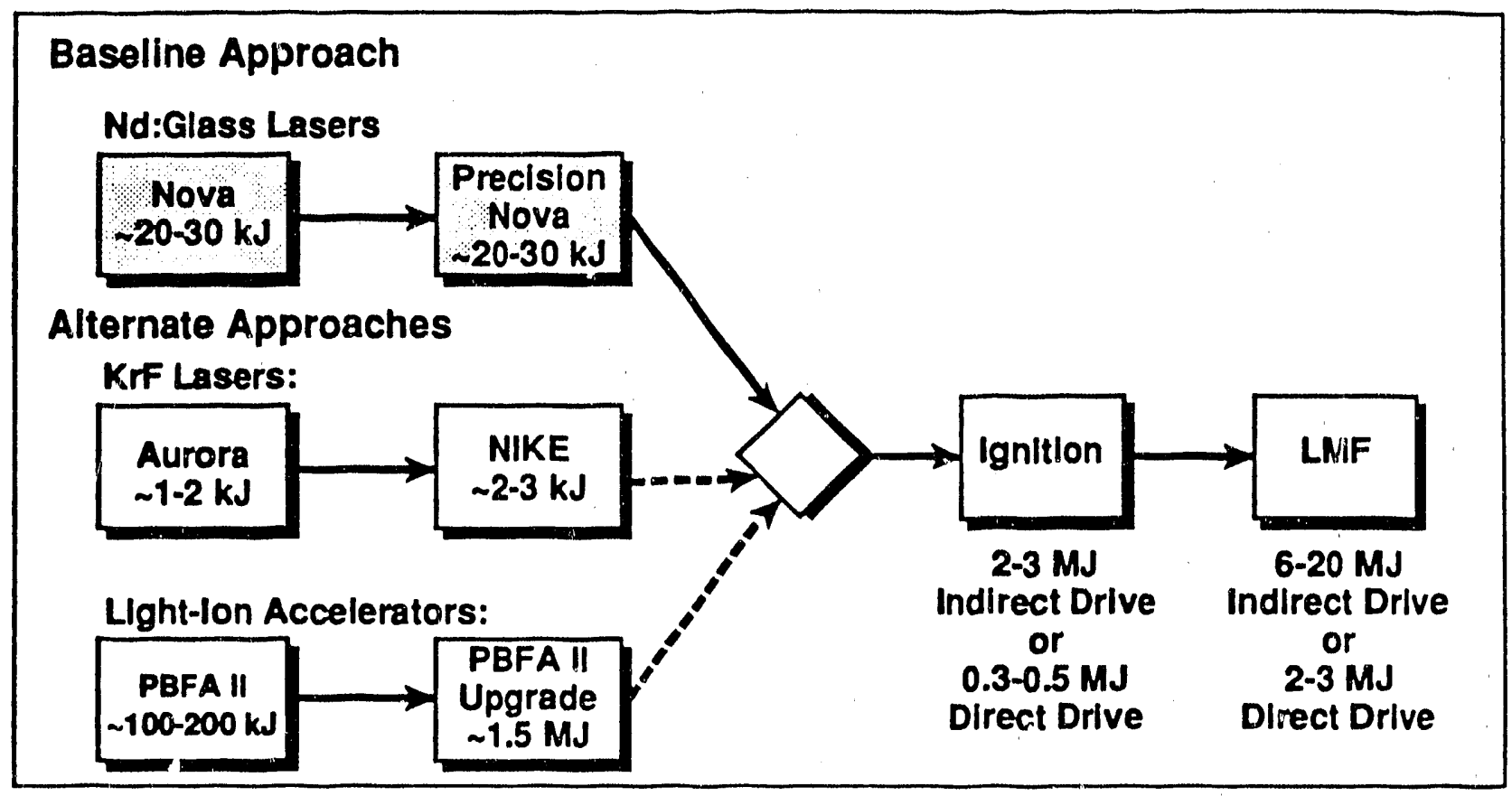

Figure 2. Two Paths to an LMF

facility and subsequent testing could be achieved at a reasonable cost, provided action is taken this year to prevent permanent loss of this laser system. Once ignition has been demonstrated and $\mathrm{KrF}$ laser technology has demonstrated that it can meet the demands for ICF energy applications, the remaining hurdles of demonstrating scalability and reliability could be undertaken.

For energy applications all of the candidate ICF drivers have the common problem of achieving a reactor design that is viable. Because of the magnitude of the difficulties in this area, any credible program aimed at ICF energy applications must have a significant contingent of personnel addressing the materials, design, and configurational problems characteristic of the reactor.

\section{The Ideal Laser Driver}

Some of the more important characteristics of an ideal ICF driver are listed in Table 1 for ICF defense applications and energy applications. Efficient target coupling, which is important for both applications, demands a laser with short wavelength, broad bandwidth, and a viable beam smoothing technique. The amount of bandwidth and the degree of smoothness needed to suppress the initiation and growth of instabilities is still a matter of debate among target experts. The ideal laser driver would have high efficiency $(\geq 5 \%)$ and would have a robust and repeatable pulse-shaping capability. For energy applications, the reliability and repairability of the laser system as well as a reasonable capability in repetitively pulsed ( 2 to 
$10 \mathrm{~Hz}$ ) operation become important. Based on current target performance understanding, the necessity for the driver to be scalable to high energies is an important characteristic for both energy and defense applications. Beam quality becomes controlling for energy applications because of the large stand-off of the final optics that is necessary to protect them from radiation damage.

Table 1. Desirable ICF Driver Characteristics

Energy Production

Efficient target coupling

- short wavelength $(<0.5 \mu \mathrm{m})$

- broad banówidth (?)

- smooth beams (?)

Low cost

High efficiency ( $>5 \%)$

Fixed repeatable pulse shape

High reliability and robustness

Repped $(2-10 \mathrm{~Hz})$

Scalable to high energies (1-10 MJ)
Defense Application

Efficient target coupling

- shor. wavelength $(<0.5 \mu \mathrm{m})$

- broad bandwidth (?)

- smooth beams (?)

Low cost

Variable pulse shape

Single -pulse

Scalable to high energies (1-10 MJ)

The KrF programs at Los Alamos, NRL, Rutherford Laboratory in England, and in Japan are geared to demonstrate that KrF lasers can naturally supply all of the performance characteristics of the ideal ICF ciriver. Multiple studies of KrF laser architectures for both single-pulse defense facilities and repetition-rate energy production facilities support the contention that these laser drivers can be constructed for costs in the few hundred dollars per joule range. The projected cost for future $\mathrm{KrF}$ facilities is based on a variety of design studies shown in Figure 3 . If the discounts for quantity, cost-per-joule reduction with size, and learning assumed in these studies are realized, then future large energy facilities will cost about $\$ 200$ to $\$ 300$ per joule. 


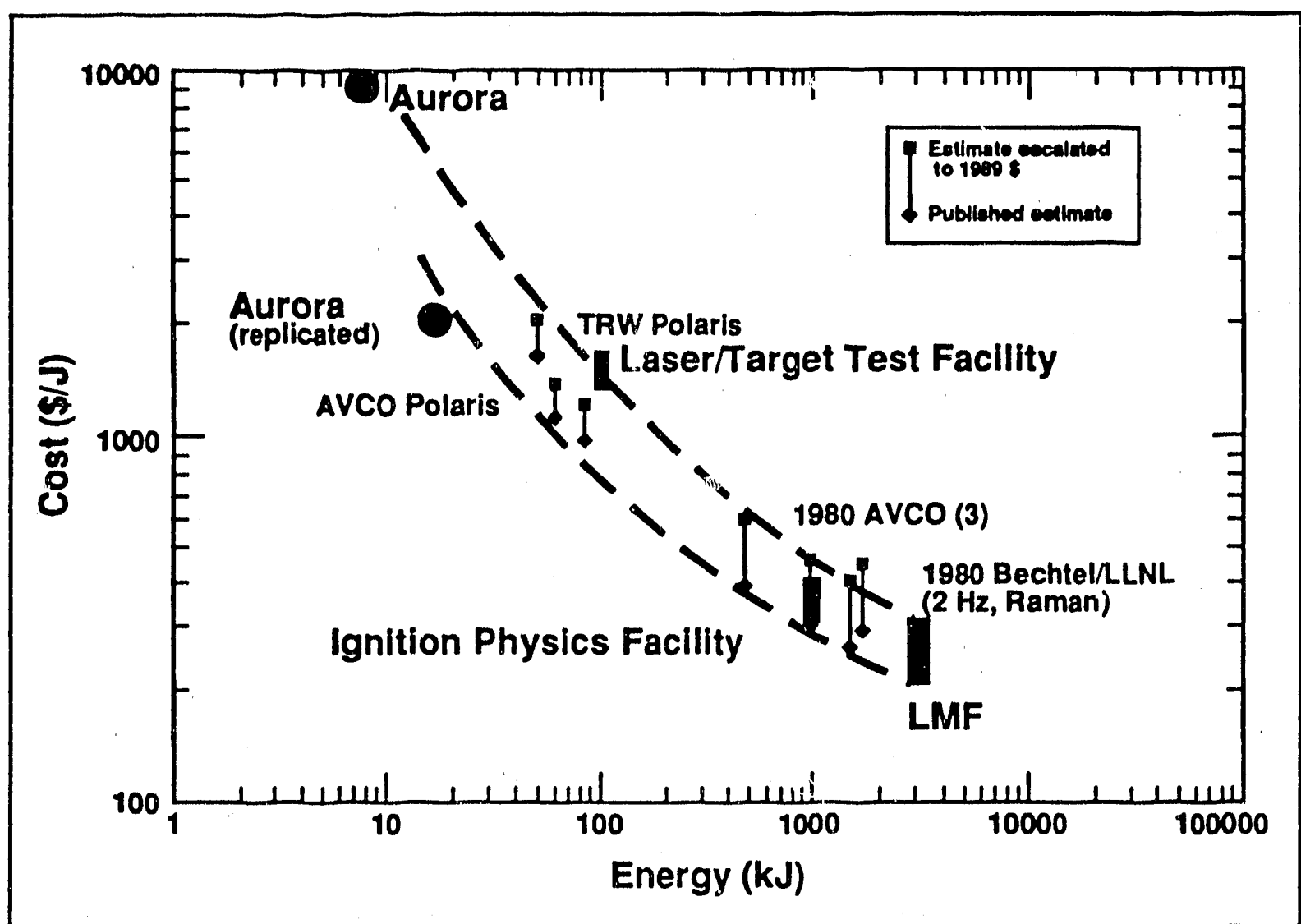

Figure 3. Los Alamos Cost Estimates are Consistent with the Results of Previous Studies

\section{Summary}

The next four years in the ICF program promise to be technically challenging for all of the candidate driver programs. Demonstrating that ignition is possible at around $1 \mathrm{MJ}$ of energy on target through experiments on NOVA and other facilities is in itself a significant undertaking. Discovering the real performance possible with direct-drive facilities through experiments on the Omega upgrade and the NIKE laser facilities will also be exciting developments. We will all be watching these developments and those associated with bringing the ion-beam technologies to a level where they are competitive with lasers. 

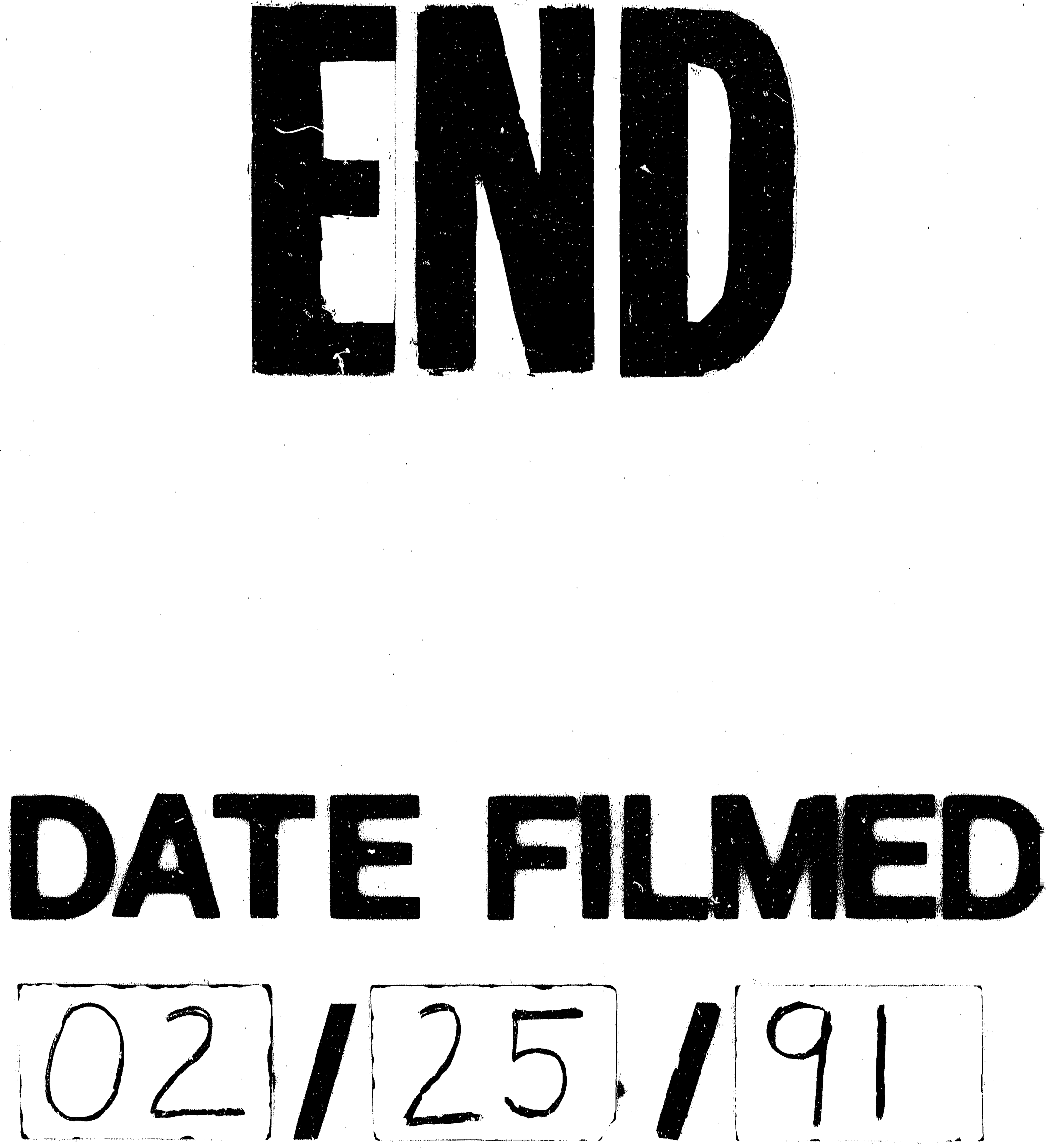
